\title{
Comparison of Segmental Mobility in Lumbar Extension Radiographs between a New Technique ("Fulcrum Bending Position") and Conventional Standing Position in Spondylolisthesis Patients
}

\author{
Pritsanai Pruttikul ${ }^{1}$, Thodsaporn Maneesrisajja ${ }^{1}$, Para Urusopon ${ }^{2}$, Tinnakorn Pluemvitayaporn ${ }^{1}$, \\ Chaiwat Piyaskulkaew ${ }^{1}$, Sombat Kunakornsawat ${ }^{1}$, Piyabuth Kittithamvongs ${ }^{1}$ \\ ${ }^{I}$ Center of Excellence in Orthopaedics, Lerdsin General Hospital, Bangkok, Thailand \\ ${ }^{2}$ Department of Radiology, Lerdsin General Hospital, Bangkok, Thailand
}

\section{Study Design: Cross-sectional study.}

Purpose: This was carried out to evaluate the benefit of a 'fulcrum bending position' compared with the standing position for evaluation of sagittal translation and sagittal rotation in symptomatic patients with spondylolisthesis.

Overview of Literature: In lumbar X-ray, the standing position is the most common position used in determining abnormalities in lumbar movement. Lack of standardized method is one of the pitfalls in this technique. We hypothesized that the new technique, that is, fulcrum bending position, may reveal a higher translation and rotation in spondylolisthesis patients.

Methods: The extension lumbar radiographs of 36 patients with low-grade spondylolisthesis were included in the analysis and measurement. Sagittal translation and sagittal rotation were measured in both the routine standing position and in our new technique, the fulcrum bending position, which involves taking lateral cross-table images in the supine position wherein the patient lies on a cylindrical pipe to achieve maximum passive back extension by the fulcrum principle.

Results: Results of the measurement of sagittal translation in both positions revealed that compared with the extension standing position, the fulcrum bending position achieved a statistically significant increase of $1.57 \mathrm{~mm}$ in translation of the vertebra position $195 \%$ confidence interval [Cl], 0.52-2.61; $p=0.004)$. The measurement of sagittal rotation in both positions revealed that when compared with the extension standing position, the fulcrum bending position achieved a statistically significant increase of $3.47^{\circ}$ in the rotation of the vertebra (95\% $\mathrm{Cl}, 1.64-5.30 ; p<0.001)$.

Conclusions: For evaluation of both sagittal translation and sagittal rotation in symptomatic patients with spondylolisthesis, compared with the extension standing position, the fulcrum bending position can achieve an increased change in magnitude. Our technique, that is, the fulcrum bending position, may offer an alternative method in the detection or exclusion of pathological mobility in patients with spondylolisthesis.

Keywords: Fulcrum bending radiograph; Spondylolisthesis; Sagittal translation; Sagittal rotation; Standing position

Received Nov 26, 2018; Revised Feb 26, 2019; Accepted Apr 13, 2019

Corresponding author: Piyabuth Kittithamvongs

Institute of Orthopaedics, Lerdsin Hospital, 190 Silom Rd. Srivieng Bangrak, Bangkok 10500, Thailand

Tel: +66-2-3539844, Fax: +66-2-3539845, E-mail: piyabuthortho@gmail.com 


\section{Introduction}

The most commonly used imaging method for the detection abnormal segmental mobility is lumbar flexionextension radiography taken in a standing position. This method is used by many surgeons in the detection of abnormal vertebral motion or as a basis for decisions regarding surgical fusion using results from the radiographs [1-4]. The range of lumbar segmental mobility is wide, but a sagittal translation of $\geq 4 \mathrm{~mm}$ or $\geq 8 \%$ is commonly accepted as a radiologic sign of pathologic mobility [3,57]. Nonetheless, questions remain regarding the use of the standing position in determining pathologic lumbar mobility owing to its lack of routine reference standard, inaccurate reproducibility, and nonstandardized techniques. Critical discussions are ongoing on the optimal patient position that can reveal maximal sagittal translation and sagittal rotation. However, in symptomatic patients, pain may prevent adequate voluntary bending of the trunk, especially in extension, which can lead to an underestimation of intervertebral motion. Furthermore, even a small difference in measurements can produce a meaningful vertebral slip, especially in low-grade spondylolisthesis. A vertebral slip can be an important criterion in deciding for or against fusion surgery. A low-grade spondylolisthesis with a sagittal translation $<5 \mathrm{~mm}$, compared with flexionextension radiographs, no longer seems to represent a criterion for fusion surgery. Therefore, a patient with 'stable' spondylolisthesis can undergo spinal decompression surgery without instrumentation $[8,9]$.

Because of this issue with standing extension radiographs, we propose a method called the 'fulcrum bending position, which may achieve maximum back extension. This position uses the fulcrum bending principle as the patient is in the supine position on a cylindrical pipe, which allows gravity to passively extend the back. In this study, we hypothesized that higher sagittal translation and sagittal rotation values will be revealed through imaging in the fulcrum bending position than in the standing position in symptomatic patients with low-grade spondylolisthesis.

\section{Materials and Methods}

An institutional review board of Lerdsin Hospital approved the research protocol in the study (IRB approval no., 0306/13/205). Written informed consent were obtained from all the participants. Patients diagnosed to have low-grade lumbar spondylolisthesis with symptomatic back pain or radicular pain by clinical and routine radiographic examination in Lerdsin Hospital from January 2015 to December 2016 were included. Patients were excluded if they had any contraindication for radiography and had undergone any spinal surgery. Based on calculations, the sample size needed was 30 patients.

\section{Radiographs}

Lateral-view images using our technique extension with fulcrum bending position were obtained in 36 patients, in addition to the routine $\mathrm{L}-\mathrm{S}$ spine radiographic views in the standard anterior-posterior, standing lateral, and standing lateral flexion-extension positions. To make sure that the distance between the patients and the X-ray source remained constant, we analyzed the images only of patients who received the radiographs in Lerdsin Hospital, Bangkok, Thailand. The distance between the X-ray source and the patient during plain and functional radiography was $1.15 \mathrm{~m}$. The X-ray cassette was placed as close as possible to the patients. All radiographs were digitally available in our hospital archives.

The method of Dupuis et al. [3] was used to analyze the sagittal translation and sagittal rotation values (Fig. 1). Translational displacement was measured in absolute values and percentages of the upper vertebral body width. To validate the assessed data, two different clinicians independently performed the measurements.
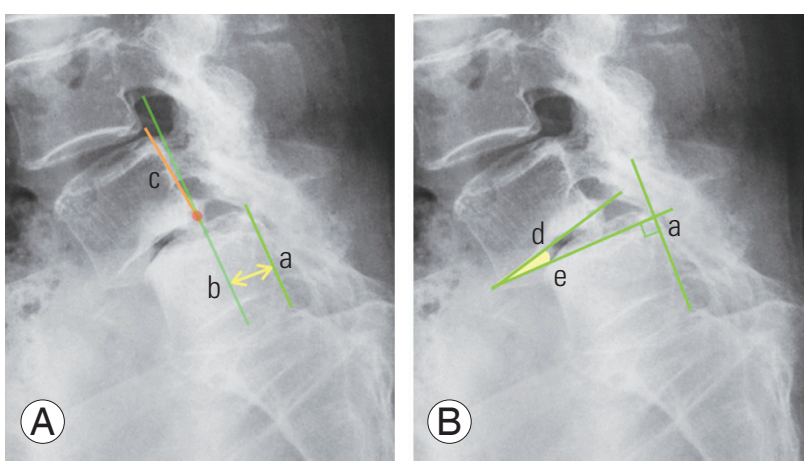

Fig. 1. Lateral radiograph of the lumbar spine showing the measurement technique of Dupuis et al. [3]. The perpendicular distance between parallel lines ' $a$ ' and ' $b$ ' defines the sagittal translation. The angle between the inferior endplate of the superior vertebra (line ' $d$ ') and the superior endplate of the inferior vertebra (line ' $e$ ') at the spondylolisthesis defines the sagittal rotation. 

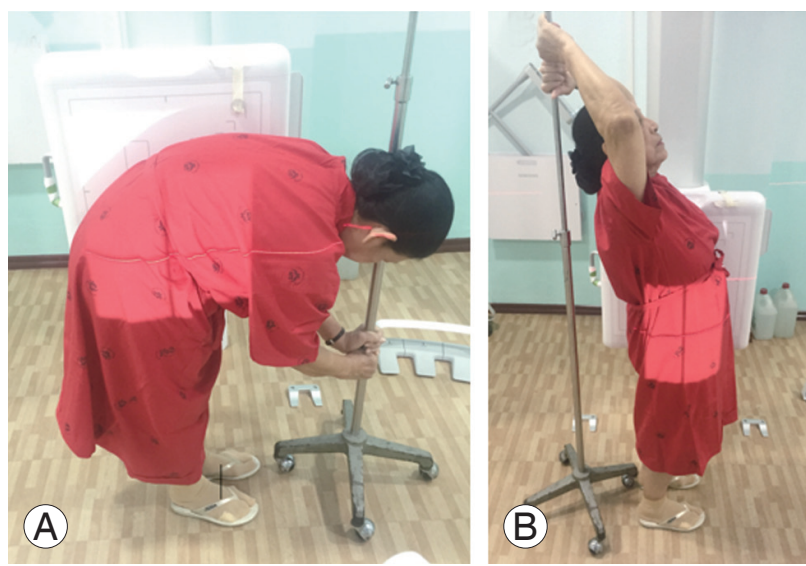

Fig. 2. Radiographs in the standing-flexion (A) and extension (B) positions. The distance between the $\mathrm{X}$-ray source and the patient during radiography was $1.15 \mathrm{~m}$. The $\mathrm{X}$-ray cassette was placed as close as possible to the patient.
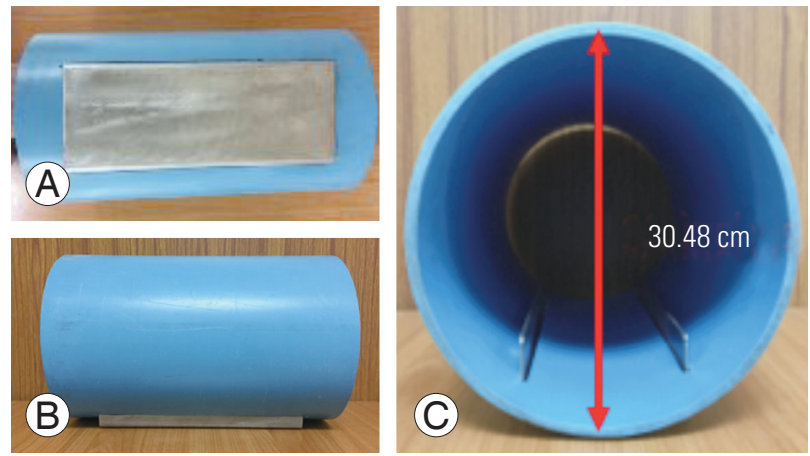

Fig. 3. (A-C) Fulcrum bending pipe. It is a cylindrical PVC pipe, with a diameter of $30.48 \mathrm{~cm}$ and length of $60.96 \mathrm{~cm}$. To stabilize the pipe from movement when the patient lies on top of the pipe, a thin, Ushaped metal piece is inserted underneath the pipe.

\section{Positioning technique}

In the standing position, the patients were asked to voluntarily lean their trunk forward and backward as much as possible (Fig. 2), after which they were positioned in the fulcrum bending position. The patients lied down supine on a flat-top table and were then asked to lift their back away from table with their legs. The technician then put a 30.48-cm-diameter cylindrical PVC pipe (Fig. 3) into the space between the patient's back and the table. The patients laid their back on the top of the pipe, and then they passively let the upper trunk extend backward. The iliac crest was adjusted so that it lies on top of the pipe (Fig. 4). Radiography was performed in a lateral cross-table view where the distance between the X-ray source and the patients was $1.15 \mathrm{~m}$. The X-ray cassette was placed close to the patients as much as possible [10].
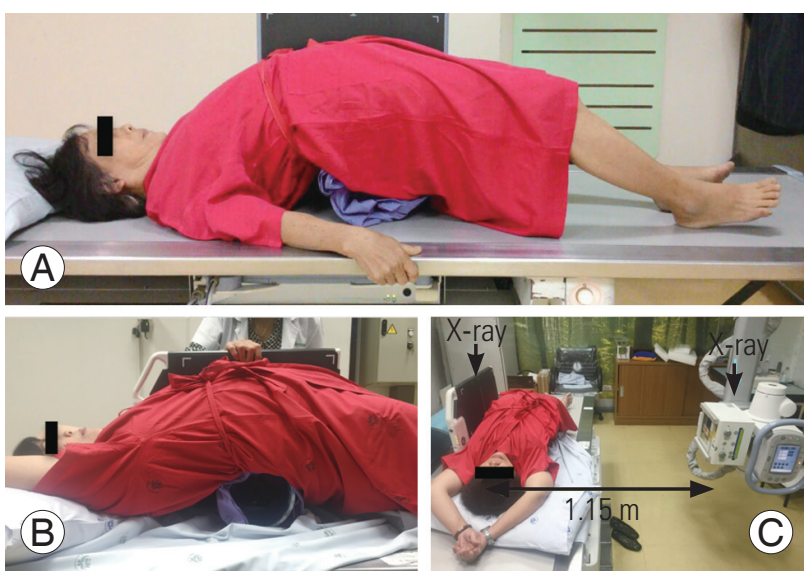

Fig. 4. Position in the fulcrum bending technique. The patient lies supine on the pipe. The top of the pipe was at the level of the iliac crest, allowing the patient's trunk to passively extend backward (A, B). The distance between the $X$-ray source and the patient during radiography was $1.15 \mathrm{~m}$. The $X$-ray cassette was placed as close as possible to the patient (C).
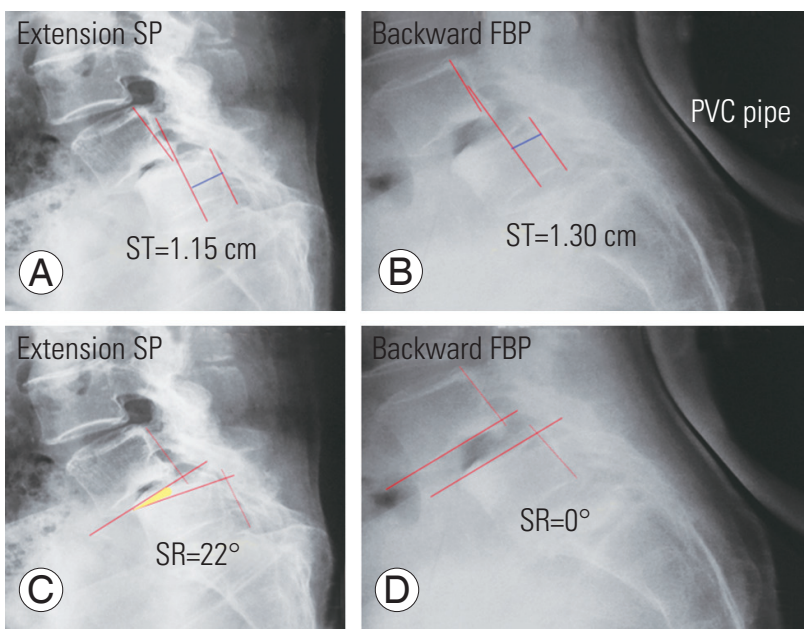

Fig. 5. Lateral extension radiographs of the lumbar spine comparing the two techniques. (A, B) Pictures A (SP) and B (FBP) show sagittal translation. (C, D) Picture C (SP) and D (FBP) show sagittal rotation. This is performed according to the measurement technique of Dupuis et al. [3]. SP, standing position; FBP, fulcrum bending position.

\section{Data analysis}

Sagittal translation and sagittal rotation were defined as the differences in translation and rotation from the flexion standing position to the extension position, respectively. In the standing position, the sagittal translation or sagittal translation can be calculated as flexion in the standing position minus extension in the standing position. In the fulcrum bending position, the values are calculated by flexion in the standing position minus extension in the 
fulcrum bending position (Fig. 5). A DICOM-based computer software program (UniWeb; EBM Technologies Inc., Taipei, Taiwan) was used to aid in performing the measurements. The values are expressed as means and standard deviations. Statistical analysis was performed using the paired $t$-test for the outcomes and intraclass correlation coefficient for reliability. Along with the comparison of absolute and relative values, analyses were conducted to determine the ability to detect a pathologic sagittal translation and sagittal rotation, as defined by previous studies (i.e., sagittal translation of $\geq 4 \mathrm{~mm}$ or $\geq 8 \%$ at L1-L5 and $\geq 6 \%$ at L5-S1 and sagittal rotation of $\geq 10^{\circ}$ at L1-L5 and $\geq 2^{\circ}$ at L5-S1), through the various positions (i.e., standing

Table 1. Gender, age, type, level, and grading

\begin{tabular}{lc} 
Characteristic & Value \\
Population & 36 \\
\hline Gender & \\
\hline Female & $32(89.0)$ \\
\hline Male & $4(11.0)$ \\
\hline Age (yr) & $51(18-72)$ \\
\hline$<20$ & $1(2.9)$ \\
\hline $21-40$ & $6(17.1)$ \\
\hline $41-60$ & $16(45.7)$ \\
\hline$>60$ & $12(34.3)$ \\
\hline Type of spondylolisthesis & \\
\hline Isthmic & $29(81.0)$ \\
\hline Degenerative & $7(19.0)$ \\
\hline Grade of spondylolisthesis & \\
\hline Grade I & $34(94.0)$ \\
\hline Grade II & $2(6.0)$ \\
\hline Level of interest & $9(25.0)$ \\
\hline L1-2 & 0 \\
\hline L2-3 & 0 \\
\hline L3-4 & $3(8.0)$ \\
\hline L4-5 & $24(67.0)$ \\
\hline L5-S1 & \\
\hline
\end{tabular}

Values are presented as number, number (\%), or mean (range), unless otherwise stated. position and fulcrum bending position) $[7,11]$.

\section{Results}

A total of 36 patients were included in this study, most of which were women $(n=32)$, with only a few men $(n=4)$. The age of the patients ranged from 18 to 72 years (mean, 51 years). All patients had spondylolisthesis (grade I in 34 cases and grade II in two cases), with most $(\mathrm{n}=29)$ having an isthmic type and experiencing claudication, back pain, and sciatica. Most patients had spondylolisthesis at L4-L5 (Table 1).

\section{Sagittal translation}

A higher degree of translation was revealed by the fulcrum bending position when compared with the standing position, with a mean difference of $1.57 \mathrm{~mm}(p=0.004)$ (Table 2). The subgroup analysis revealed a statistically significant difference in patients younger than 60 years $(p=0.024)$ and those with degenerative type $(p=0.001)$ and L1-L4 level $(p=0.006)$ spondylolisthesis but not in patients older than 60 years $(p=0.136)$ and those with isthmic type $(p=0.310)$ and L5-S1 level $(p=0.638)$ spondylolisthesis (Table 3).

\section{Sagittal rotation}

Compared with the standing position, the fulcrum bending position showed a remarkably superior degree of rotation, with a mean difference of $3.47^{\circ}(p<0.001)$ (Table 4). This was statistically significant in patients of all age groups and affected levels but not in patients with isthmic spondylolisthesis $(p=0.064)$ (Table 3 ).

\section{Reliability of measurement}

Good intraobserver and interobserver reliabilities were found for both positions (Table 5).

Table 2. Sagittal translation

\begin{tabular}{lcccc} 
Technique & Mean translation \pm standard deviation $(\mathrm{mm})$ & Mean difference $(\mathrm{mm})$ & $p$-value & $95 \%$ Confidence interval \\
\hline Standing & $4.6 \pm 4.95$ & 1.57 & 0.004 & $0.52-2.61$ \\
\hline Fulcrum & $6.2 \pm 4.62$ & & & \\
\hline
\end{tabular}


Table 3. Subgroup analysis by age, type of spondylolisthesis, and level of interest

\begin{tabular}{|c|c|c|c|c|c|c|c|c|c|}
\hline Variable & Technique & $\begin{array}{c}\text { Mean } \\
\text { translation } \pm S D \\
(\mathrm{~mm})\end{array}$ & $\begin{array}{c}\text { Mean } \\
\text { difference } \\
(\mathrm{mm})\end{array}$ & $p$-value & $95 \% \mathrm{Cl}$ & $\begin{array}{c}\text { Mean } \\
\text { rotation } \pm S D \\
\left({ }^{\circ}\right)\end{array}$ & $\begin{array}{c}\text { Mean } \\
\text { difference } \\
\left(^{\circ}\right)\end{array}$ & $p$-value & $95 \% \mathrm{Cl}$ \\
\hline \multicolumn{10}{|l|}{ Age (yr) } \\
\hline \multirow[t]{2}{*}{$<60$} & Standing & $0.58 \pm 3.10$ & 1.66 & 0.024 & 0.24 to 3.08 & $3.10 \pm 5.98$ & 3.06 & 0.030 & 0.33 to 5.79 \\
\hline & Fulcrum & $2.23 \pm 3.61$ & & & & $6.16 \pm 8.56$ & & & \\
\hline \multirow[t]{2}{*}{$\geq 60$} & Standing & $0.40 \pm 3.96$ & 0.73 & 0.136 & -0.56 to 3.61 & $2.60 \pm 3.77$ & 3.60 & 0.001 & 1.85 to 5.35 \\
\hline & Fulcrum & $1.13 \pm 3.14$ & & & & $6.20 \pm 4.72$ & & & \\
\hline \multicolumn{10}{|l|}{$\begin{array}{l}\text { Type of spondy- } \\
\text { lolisthesis }\end{array}$} \\
\hline \multirow[t]{2}{*}{ Isthmic } & Standing & $0.21 \pm 3.58$ & 0.92 & 0.310 & -0.94 to 2.78 & $2.47 \pm 6.27$ & 2.39 & 0.064 & -0.33 to 5.79 \\
\hline & Fulcrum & $1.14 \pm 4.30$ & & & & $5.89 \pm 9.56$ & & & \\
\hline \multirow[t]{2}{*}{ Degenerative } & Standing & $0.23 \pm 2.74$ & 1.68 & 0.001 & 1.16 to 3.60 & $3.83 \pm 4.3$ & 3.44 & $<0.001$ & 1.96 to 4.92 \\
\hline & Fulcrum & $2.09 \pm 3.16$ & & & & $7.26 \pm 4.3$ & & & \\
\hline \multicolumn{10}{|l|}{ Level of interest } \\
\hline \multirow[t]{2}{*}{ L1-L4 level } & Standing & $0.20 \pm 2.88$ & 2.08 & 0.006 & 0.66 to 3.49 & $3.40 \pm 5.71$ & 2.71 & 0.014 & 0.60 to 4.82 \\
\hline & Fulcrum & $2.28 \pm 3.35$ & & & & $6.11 \pm 7.28$ & & & \\
\hline \multirow[t]{2}{*}{ L5-S1 level } & Standing & $0.65 \pm 4.02$ & 0.32 & 0.638 & -1.84 to 1.19 & $2.30 \pm 6.64$ & 5.43 & 0.039 & $\begin{array}{l}0.36 \text { to } \\
10.48\end{array}$ \\
\hline & Fulcrum & $0.33 \pm 4.45$ & & & & $7.73 \pm 8.35$ & & & \\
\hline
\end{tabular}

SD, standard deviation; $\mathrm{Cl}$, confidence interval.

Table 4. Sagittal rotation

$\begin{array}{lcccc}\text { Technique } & \text { Mean rotation } \pm \text { standard deviation }\left({ }^{\circ}\right) & \text { Mean difference }\left(^{\circ}\right) & p \text {-value } & 95 \% \text { Confidence interval } \\ \text { Standing } & 5.49 \pm 12.93 & 3.47 & <0.001 & 1.64-5.30 \\ \text { Fulcrum } & 8.96 \pm 9.86 & & & \end{array}$

Table 5. Reliability of measurement

\begin{tabular}{lccccc} 
& \multicolumn{2}{c}{ Intra-observer reliability } & \multicolumn{2}{c}{ Inter-observer reliability } \\
\cline { 2 - 3 } \cline { 5 - 6 } Technique & Intra-class correlation coefficient & $95 \% \mathrm{Cl}$ & & Intra-class correlation coefficient & $95 \% \mathrm{Cl}$ \\
Standing & 0.87 & $0.84-0.88$ & 0.81 & $0.80-0.82$ \\
Fulcrum & 0.87 & $0.87-0.89$ & 0.82 & $0.81-0.83$ \\
\hline
\end{tabular}

$\mathrm{Cl}$, confidence interval.

\section{Discussion}

This study shows that in most of the 36 symptomatic patients with low-grade spondylolisthesis included, radiography in the fulcrum bending position produces a greater sagittal translation value than the standard standing position does. Sagittal rotation was also more distinct with the fulcrum bending position than with the standing position.
Whereas the standard standing position had a pathologic sagittal translation in only $5 \%$ of cases, the fulcrum bending position revealed a pathologic sagittal translation in $17 \%$ of cases. Our interobserver error is comparable with those of other studies and did not affect the statistical results $[12,13]$.

Abnormal translation seems to be increased in the standing position when compared with other positions [12-17]. 
Thus, the standard imaging technique used to reveal maximal segmental motion is the dynamic flexion extension radiograph $[1,2,18]$. Pain leads to decreased intervertebral motion in symptomatic patients with spondylolisthesis [19]. Acceptable functional radiographs depend on the patient's effort and cooperation and on the examiner's proper control; when these factors change, motivation can lead to different results from test to test [20]. Compared with imaging in a standing position with activation of the back muscles, imaging in a fulcrum bending supine position (with the muscles in a relaxed state and gravity allowed to passively extend the back) identified $17 \%$ of patients with a pathologic segmental mobility that was apparent in only $5 \%$ of patients in the standing position.

In addition, greater values of sagittal rotation could be assessed in the fulcrum bending position. Interestingly, in all cases, increased sagittal rotation did not accompany pathological sagittal translation. An explanation for this could be the degenerative changes in the intervertebral space and the facet joint that may hinder an adequate angular motion. In our study, pathological sagittal rotation was detected in $19 \%$ of cases through the flexion bending position and in $5 \%$ of cases through the standing position. This is consistent with the high variation and limited clinical value of sagittal rotation shown in other studies $[13,16,21]$. The pathogenesis of an isthmic and a degenerative spondylolisthesis is different, as are often the age, physical condition, and symptoms of the patients. Therefore, the mixture of both patient groups presents a potential bias in such a study.

Radiograph with the fulcrum bending position was used to accurately predict scoliosis curve correction [10]. We applied this technique to determine the correction of spondylolisthesis in sagittal translation and rotation because it allows an excellent degree of deformity correction. Compared to the standard standing position, this position provides higher values in both sagittal translation and sagittal rotation.

A remarkably higher magnitude of translation and rotation was achieved in the standing position than the fulcrum bending position in flexion radiography because the abdomen limits lumbar motion when the patient is supine on the cylindrical pipe. Therefore, we still acknowledge that the standing position is the standard procedure for flexion radiography. Most patients with spinal instability experience more pain when they extend backward than from forward flexion. We assume that pain is not a problem when the patients perform flexion radiography, so underestimation of occult instability is less when compared to extension radiography.

The study has several limitations that must be considered. First, there was lack of variety in patient characteristics. Future studies need to address this issue. Second, computed tomography (CT) is considered as the most accurate tool for the assessment of the degree of slip, but the patient must be examined in the supine position. Obtaining CT images is technically challenging, and from a financial point of view, it is probably not available in every institute. Third, long-term follow-up result may have a benefit, particularly for the undetected instability in the standing position group. Other clinical applications of a backward fulcrum bending position could be done to determine the surgical reduction or deformity correction required in high-grade spondylolisthesis and sagittal imbalance.

\section{Conclusions}

The fulcrum bending position achieved a higher magnitude of translation and rotation than did the standing position in the evaluation of sagittal translation in symptomatic patients with spondylolisthesis with limited lumbar extension due to pain. Our technique of fulcrum bending position provides an alternative method for the detection or exclusion of pathological mobility in surgical cases that require decision-making for management with spinal fusion.

\section{Conflict of Interest}

No potential conflict of interest relevant to this article was reported.

\section{References}

1. Pitkanen MT, Manninen HI, Lindgren KA, Sihvonen TA, Airaksinen O, Soimakallio S. Segmental lumbar spine instability at flexion-extension radiography can be predicted by conventional radiography. Clin Radiol 2002;57:632-9.

2. Guyer RD, McAfee PC, Banco RJ, et al. Prospective, randomized, multicenter Food and Drug Administration investigational device exemption study of lumbar total disc replacement with the CHARITE 
artificial disc versus lumbar fusion: five-year followup. Spine J 2009;9:374-86.

3. Dupuis PR, Yong-Hing K, Cassidy JD, Kirkaldy-Willis WH. Radiologic diagnosis of degenerative lumbar spinal instability. Spine (Phila Pa 1976) 1985;10:26276.

4. Kirkaldy-Willis WH, Farfan HF. Instability of the lumbar spine. Clin Orthop Relat Res 1982;165:11023.

5. Morgan FP, King T. Primary instability of lumbar vertebrae as a common cause of low back pain. J Bone Joint Surg Br 1957;39-B:6-22.

6. Kanemura A, Doita M, Kasahara K, Sumi M, Kurosaka M, Iguchi T. The influence of sagittal instability factors on clinical lumbar spinal symptoms. J Spinal Disord Tech 2009;22:479-85.

7. Posner I, White AA 3rd, Edwards WT, Hayes WC. A biomechanical analysis of the clinical stability of the lumbar and lumbosacral spine. Spine (Phila Pa 1976) 1982;7:374-89.

8. Thome C, Zevgaridis D, Leheta O, et al. Outcome after less-invasive decompression of lumbar spinal stenosis: a randomized comparison of unilateral laminotomy, bilateral laminotomy, and laminectomy. J Neurosurg Spine 2005;3:129-41.

9. Epstein NE. Decompression in the surgical management of degenerative spondylolisthesis: advantages of a conservative approach in 290 patients. J Spinal Disord 1998;11:116-22.

10. Cabraja M, Mohamed E, Koeppen D, Kroppenstedt $\mathrm{S}$. The analysis of segmental mobility with different lumbar radiographs in symptomatic patients with a spondylolisthesis. Eur Spine J 2012;21:256-61.

11. Nachemson AL, Schultz AB, Berkson MH. Mechanical properties of human lumbar spine motion seg- ments: influence of age, sex, disc level, and degeneration. Spine (Phila Pa 1976) 1979;4:1-8.

12. Friberg O. Lumbar instability: a dynamic approach by traction-compression radiography. Spine (Phila $\mathrm{Pa}$ 1976) 1987;12:119-29.

13. Wood KB, Popp CA, Transfeldt EE, Geissele AE. Radiographic evaluation of instability in spondylolisthesis. Spine (Phila Pa 1976) 1994;19:1697-703.

14. Lowe RW, Hayes TD, Kaye J, Bagg RJ, Luekens CA. Standing roentgenograms in spondylolisthesis. Clin Orthop Relat Res 1976;117:80-4.

15. Penning L, Blickman JR. Instability in lumbar spondylolisthesis: a radiologic study of several concepts. AJR Am J Roentgenol 1980;134:293-301.

16. Hayes MA, Howard TC, Gruel CR, Kopta JA. Roentgenographic evaluation of lumbar spine flexionextension in asymptomatic individuals. Spine (Phila Pa 1976) 1989;14:327-31.

17. Pennal GF, Conn GS, McDonald G, Dale G, Garside H. Motion studies of the lumbar spine: a preliminary report. J Bone Joint Surg Br 1972;54:442-52.

18. Wiltse LL, Hutchinson RH. Surgical treatment of spondylolisthesis. Clin Orthop Relat Res 1964;35: 116-35

19. Pearcy M, Portek I, Shepherd J. The effect of lowback pain on lumbar spinal movements measured by three-dimensional X-ray analysis. Spine (Phila Pa 1976) 1985;10:150-3.

20. Quinnell RC, Stockdale HR. Flexion and extension radiography of the lumbar spine: a comparison with lumbar discography. Clin Radiol 1983;34:405-11.

21. Panjabi M, White AA 3rd. A mathematical approach for three-dimensional analysis of the mechanics of the spine. J Biomech 1971;4:203-11. 